\title{
The Effect of Competition on Men's Self-Reported Sexual Interest
}

\author{
Gregory Gorelik $^{1}$ - David F. Bjorklund ${ }^{1}$
}

Published online: 2 April 2015

(C) Springer International Publishing 2015

\begin{abstract}
Men have been sexually selected (both via malemale competition and female choice) to compete with other men for survival and reproduction. Evidence in humans suggests that men are especially competitive with other men over resources and, if successful, are valued as attractive mating prospects by women. We predicted that experimentally manipulating competitive outcomes would differentially affect men's sexual interest, with a victory resulting in men expressing greater interest in mating opportunities and a loss resulting in decreased interest in mating opportunities. One hundred thirteen men were asked to participate in a speed-based competition. Participants were randomly assigned to experience a win, a loss, or no competitive feedback (control condition). Participants' sexual interest was gauged by their responses to photographs of women of differing attractiveness, wherein they were asked to rate their sexual interest in the photographed women and to give attributions of sexual interest to the same women. Results showed that single (unmated) men exhibited the predicted effects of competition on sexual interest. Specifically, whereas both single men and mated men were more sexually interested in high-attractiveness women than in low-attractiveness women, only single men exhibited a higher sexual interest after a win, followed by the control and losing conditions, respectively.
\end{abstract}

Keywords Sexual selection · Competition · Life history theory $\cdot$ Sexual interest

Gregory Gorelik

gregory.gorelik33@gmail.com

1 Department of Psychology, Florida Atlantic University, Boca Raton, FL 33431, USA

\section{The Effect of Competition on Men's Sexual Interest}

In line with Darwin's (1871/2006) theory of sexual selection, success in competitive contexts with other men presumably allowed our male ancestors to defeat their reproductive rivals and to attract mates. In addition to direct physical altercations that pervade much of the animal world, most such male-male competition in humans centers on conflicts over social status. For example, women find men who have resources (and, thus, who are of a higher social status) attractive, which explains why intrasexual competition between men occurs mostly in the realm of resource acquisition (Buss 1989; Shackelford et al. 2005). The universality of this preference is corroborated by Buss' (1989) cross-cultural survey of 37 societies, which revealed that women placed greater value than men on socialstatus signaling traits such as good financial prospects, earning capacity, and ambition/industriousness in long-term romantic partners. That women prefer men who are of a high social status is likewise evident from the finding that women expect to be more upset by a potential mate's lying about his social status and resource holdings than by other types of deception (Haselton et al. 2005). That men target other men's resource holdings in contexts of intrasexual competition is highlighted by the fact that men are more likely to derogate other men's resources, goals, and achievements, whereas women are more likely to derogate other women's sexual behavior and appearance (Buss and Dedden 1990).

In what follows, we discuss the possibility that, in addition to their effect on eliminating sexual rivals and attracting mates, the outcomes of men's intrasexual competition over social status may also lead to changes in competitors' sexual. More specifically, we hypothesize that, in addition to the physiological and psychological mechanisms that regulate men's likelihood of initiating and continuing competitions with reproductive rivals, men also exhibit mechanisms whose 
evolved function is the conditional regulation of sexual following different competitive outcomes (i.e., winning or losing).

\section{The Effects of Competition on Men's Physiological and Psychological States}

The effects of competition on men's physiological and psychological states have been examined in a growing number of studies. For example, Markey and Markey $(2011,2012)$ showed that rates of Internet pornography searches increased in states that overwhelmingly voted for winning candidates and decreased in states that overwhelmingly voted for losing candidates (as tracked across U.S. presidential and congressional elections). Other studies, while not directly examining the effects of winning a competition on men's sexual interest, have reported that victories in competitive contexts such as basketball games (Gonzalez-Bono et al. 2000) and chess tournaments (Mazur et al. 1992), or even being a fan of a winning sports team or a proponent of a winning political party (Bernhardt et al. 1998; Stanton et al. 2009), led to increases in men's testosterone levels, whereas losses led to decreases (see Archer 2006, for a discussion of the challenge hypothesis). Gladue et al. (1989) also demonstrated that chancedetermined competitive outcomes following a contrived speed-based button-pressing competition increased salivary testosterone in winning men and decreased it in losing men. Even the driving of a luxury automobile is associated with increases in men's testosterone, suggesting that it is changes in social status that are responsible for these competition-induced changes in testosterone (Saad and Vongas 2009). Given the relationship between levels of testosterone and sex drive (Rupp and Wallen 2007), it is likely that increases in testosterone as a result of winning a competition might translate into increases in sexual interest.

Life history theory (Ellis 2004; Hill and Kaplan 1999) may explain this sensitivity of men's sexual interest to winning or losing competitions. According to life history theory, animals allocate their time and metabolic resources in an evolutionarily adaptive manner across the life-span. These allocation-ofenergy decisions often center on the tradeoff between investing in current versus future reproduction and may be sensitive to contextual circumstances. For example, by ascending in social rank, a man is primed to invest in current reproductive effort. By descending in social rank, however, a man is primed to invest in future reproductive effort-a response that would save him from violent territorial competitions with other, more socially dominant men, from the risk of wasting time, resources, and further social standing by pursuing women who are not interested in him, and from the immunosuppressive effects of testosterone (Alonso-Alvarez et al. 2007).

\section{The Present Study}

That even vicariously winning or losing a competition can presumably have significant effects on men's level of testosterone and sexual interest suggests that an experimental manipulation of a firsthand victory or loss may produce an even larger effect on men's sexual interest. In the current study, we predicted that, after experimentally priming men with experiences of either winning or losing a competition against another man, men in the winning condition would show a greater sexual interest than men in the losing condition, as gauged by their responses to women's photographs. Sexual interest was measured with two sets of questions: (1) questions gauging participants' own sexual interest as it related to the women pictured in the photographs (Participant Sexual Interest) and (2) questions gauging participants' attribution of sexual interest to the same women (Target Sexual Interest). That Target Sexual Interest may be indicative of participants' sexual interest is predicted by error management theory (Haselton and Buss 2000), which states that men's reproductive interests are best served by erring on the side of perceiving more sexual interest in women than there may actually be. Therefore, assuming that men's over-perception of women's sexual interest reflects their own sexual interest, we predicted an increase in participants' attribution of sexual interest to women as a function of winning an intrasexual competition against a reproductive rival. In contrast, men who experience defeat should retreat from potentially costly competition and mate-acquisition behaviors and should therefore under-perceive women's sexual interest. We predicted that this effect would be especially large for women judged to be highly attractive relative to women judged to be less attractive. Gladue et al. (1989) “competitive" task (see Methods), which previously showed differences in participants' testosterone levels following differential competitive outcomes, was adapted for the present study. Furthermore, because testosterone and mate-seeking behavior show a decline in men who are in committed long-term relationships and in men who become fathers (e.g., Gettler et al. 2011, 2011; Gray et al. 2002; McIntyre et al. 2006), a measure of participants' sexual relationship status was also included.

Although previous studies have shown correlations between political victories and pornography viewing (i.e., Markey and Markey 2010, 2011), as well as changes in men's testosterone level as a result of winning or losing a competition (e.g., Bernhardt et al. 1998; Gonzalez-Bono et al. 2000; Gladue et al. 1989; Mazur et al. 1992; Stanton et al. 2009), to our knowledge, this is the first experimental study to investigate the effects of winning or losing a competition on men's sexual interest. 


\section{Methods}

\section{Population}

One hundred thirteen male undergraduates (age $M=19.59$, $S D=3.4 ; 16$ participants failed to report their age) from a public university in the Southeastern US were recruited from Introduction to Psychology courses and given course credit for participation. Of the initial 113 participants, 17 were excluded from the sample due to either guessing the study's hypothesis or failing to follow instructions (14 participants), for having a sexual orientation that was other than "straight" or "heterosexual" ( 3 participants - one of whom was also included among the previously mentioned 14 "guessers"), or for computer error (1 participant), yielding a total of 96 participants. An additional two participants did not finish the Participant Sexual Interest portion of the questionnaire (see below) due to computer error.

\section{Materials}

Participants were asked to engage in a computer-based, button-pressing reaction-time task (adapted from Gladue et al. 1989; see Procedure) as a manipulation of competitive priming on participants' sexual interest. Upon completion of the reaction-time task, participants answered a series of Likerttype questions in response to photographs of women presented on a computer monitor (see Table 1). These questions gauged participants' own sexual interest in the photographed women (Participant Sexual Interest) and their attribution of sexual interest to the same women (Target Sexual Interest).

All of the questions pertained to photographs of women's faces $(n=4)$, divided into two groups of high attractiveness and low attractiveness, as previously measured on a 1-10 Likert-type scale by a separate sample of university students $(N=45$; 29 women, 16 men; there were no significant differences between men's and women's ratings). Of the initial ten photographs, the two highest rated were used as the highattractiveness targets, and the two lowest rated were used as the low-attractiveness targets. Photographs were obtained from the FACES database compiled by Ebner et al. (2010). Each participant was presented with two of the four photographs (one of high attractiveness and one of low attractiveness) and asked the same set of questions regarding each photograph.

\section{Procedure}

Upon arrival in the laboratory, participants were told that they would undergo a series of tests that would measure their reaction time and their ability to read facial expressions. Participants were randomly assigned to one of three between-subject groups (two experimental, one control;
Table 1 Non-sex questions, target sexual interest questions, and participant sexual interest questions (rated on an eight-point scale: $1=$ "not at all"; $8=$ "very")

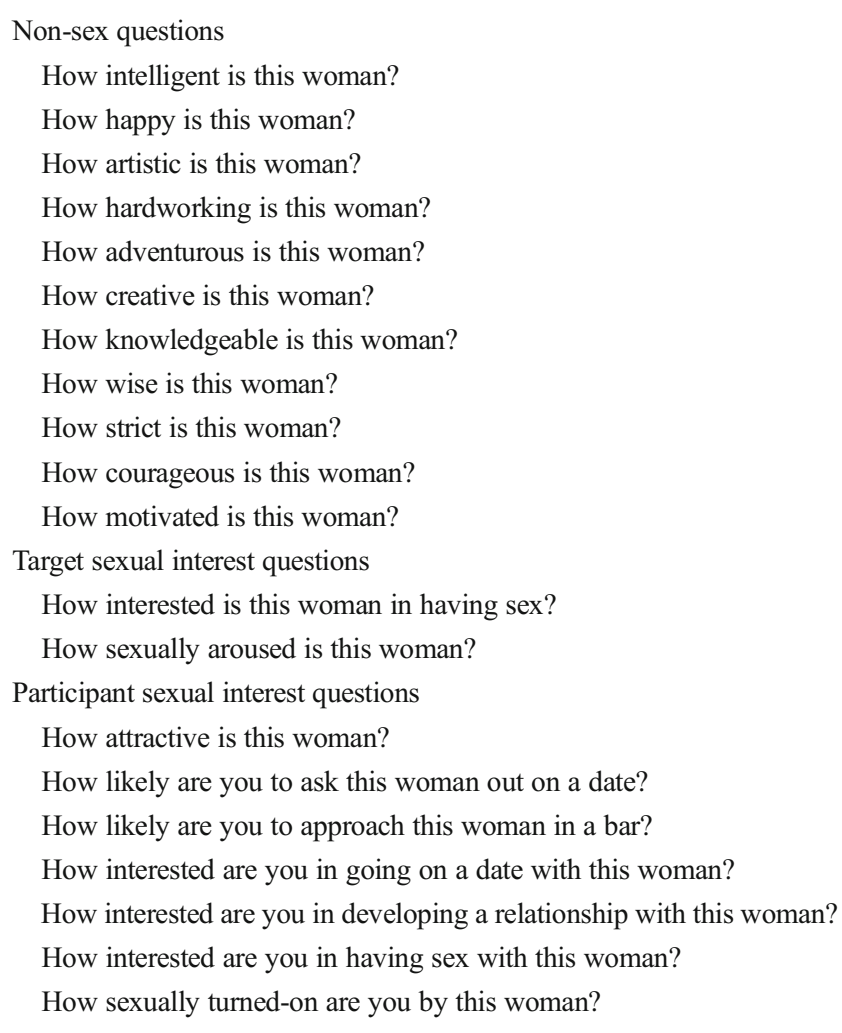

winning group, $n=32$; losing group, $n=28$; control group, $n=36$ ). Participants in the experimental groups were primed with an intrasexual competition scenario by being told that they were competing for the fastest reaction time with another male participant from a different university who was matched to them on age and whose photograph they were shown. Participants in the control group were not told that they were competing with another participant. Following a modified version of Gladue et al. (1989) manipulation of competitive outcomes, all participants were seated at a computer monitor and underwent a series of five rounds of five trials (for a total of 25 trials) in which they were asked to press a button as fast as they could following presentations of the words "WAIT," "READY," and "GO!". Participants were provided with either "winning" or "losing" feedback after each set of five trials, and with an overall "winning" or "losing" score upon completion of the reaction-time task. Feedback was given in the form of comparisons between each participant's and his "competitor's" reaction times, which were initially chosen via a random number generator and kept constant across participants (but reversed between participants in the winning and losing conditions, that is, winning participants won all but the second round of five trials, whereas losing participants lost all but the second round of five trials). Participants in the control group received no such feedback, but also engaged in the 
button-pressing task. Participants assigned to the "winning" experimental group were told that their reaction time was faster than their competitor's, whereas participants in the "losing" experimental group were told that their reaction time was significantly slower than their competitor's. Depending on condition, participants were either told that they won four of the five rounds (winning group) or that they lost four of the five rounds (losing group).

All participants were then asked to participate in a "facialexpression-reading task," which ostensibly had no connection to the reaction-time task. This facial-expression-reading task was used to gauge participants' sexual interest by measuring their response to women's photographs (Participant Sexual Interest) and their attribution of sexual interest to the women presented in these photographs (Target Sexual Interest; this measure was used to test the predictions of error management theory). Complete lists of the questions for the Participant Sexual Interest questionnaire and the Target Sexual Interest questionnaire are presented in Table 1. To reduce the likelihood of demand characteristics, the Target Sexual Interest questionnaire contained randomized sex-related and non-sex-related questions and was always administered before the Participant Sexual Interest questionnaire (with one exception-the Participant Sexual Interest question "How attractive is this woman?" was presented to participants in conjunction with the Target Sexual Interest questions, but treated as a Participant Sexual Interest question). Target Sexual Interest questions included: "How sexually aroused is this woman?" and "How interested is this woman in having sex?" Non-sexrelated questions included: "How happy is this woman?" and "How adventurous is this woman?" The Participant Sexual Interest questionnaire, on the other hand, only contained sexrelated questions. These were administered in order of increasing sexual explicitness, starting with sexually indirect questions (e.g., "How likely are you to ask this woman out on a date?" and "How likely are you to approach this woman in a bar?") and proceeding with more sexually direct questions (e.g., "How sexually 'turned on' are you by this woman?" and "How interested are you in having sex with this woman?"), both of which aimed to directly measure the participant's own sexual interest. All answers were provided on a Likert-type scale, ranging from 1 (not at all) to 8 (very). Every participant rated one highattractiveness woman and one low-attractiveness woman. Photographs were counterbalanced, and questions were randomized within the Target Sexual Interest questionnaire.

Upon completion of the facial-expression-reading task, participants were asked to complete a demographics questionnaire (assessing age, relationship status, race, sexual orientation, and estimated self and parental household income), questioned as to whether they had guessed the study's hypothesis or the fabricated nature of the competitive, buttonpressing task, and subsequently debriefed. Relationship status was measured via a "yes" or "no" answer to the question "Are you currently in a sexually active relationship?" (winning group, 14 mated, 18 single; losing group, 13 mated, 15 single; control group, 13 mated, 23 single). Overall, the study's duration took no longer than $30 \mathrm{~min}$ per participant.

\section{Results}

The data were first submitted to a factor analysis that confirmed that the classification of questions into Participant Sexual Interest and Target Sexual Interest was appropriate (see Appendix). We examined differences in the mean ratings for the Participant Sexual Interest questions as a function of condition (winning vs. losing vs. control), target attractiveness (high attractiveness vs. low attractiveness), and relationship status of the participant ("mated"-i.e., in a relationshipvs. "single"). This was followed by a similar analysis of Target Sexual Interest.

\section{Participant Sexual Interest}

Participant Sexual Interest was computed as the average of seven questions measuring participants' sexual interest in female targets on an eight-point Likert-type scale (high attractiveness, $\alpha=.94$; low attractiveness, $\alpha=.92$ ) (see Table 1). Mean Participant Sexual Interest scores by Participant Relationship Status, Competition, and Target Attractiveness are presented in Table 2. These scores were entered into a 2 (Participant Relationship Status: mated vs. single) by 3 (Competition: winning vs. losing. vs. control) by 2 (Target Attractiveness: high attractiveness vs. low attractiveness) mixed-design ANOVA, with Participant Relationship Status and Competition being between-subjects factors and Target Attractiveness being a within-subjects factor.

The analysis produced a significant main effect of Target Attractiveness, $F(1,88)=273.06, p<.001, \eta_{p}=.87$, such that high-attractiveness women were associated with higher Participant Sexual Interest ratings $(M=4.27, S D=1.71)$ than low attractiveness women $(M=1.40, S D=.83)$. There was also a significant Competition by Participant Relationship Status interaction, $F(2,88)=3.5, p=.04, \eta_{p}=.27$, such that the predicted effect of Competition was observed in the Participant Sexual Interest ratings of single participants. Tukey's honestly significant difference (HSD) follow-up tests $(p<0.05)$ revealed that single participants in the winning condition showed significantly higher Participant Sexual Interest ratings $(M=3.25, S D=.72)$ than single participants in the losing condition $(M=2.25, S D=.81)$. Single participants in the control condition showed an intermediate Participant Sexual Interest rating $(M=2.77, S D=.93)$ that did not differ significantly from the ratings of participants in either the winning or losing conditions. A contrast analysis (Rosenthal et al. 2000) revealed a significant linear trend such that single participants' 
Table 2 Means and standard deviations for participant sexual interest by relationship status, competition condition, and target attractiveness (rated on an eight-point scale, $1=$ "not at all"; $8=$ "very")

\begin{tabular}{|c|c|c|c|c|c|c|}
\hline & & \multicolumn{3}{|l|}{ Condition } & \multirow[t]{2}{*}{ Marginal means } & \\
\hline & & Winning & Losing & Control & & \\
\hline $\begin{array}{l}\text { Total mated participants, } \\
\qquad M=2.93\end{array}$ & $\begin{array}{l}\text { HA targets } \\
\text { LA targets }\end{array}$ & $\begin{array}{l}M=4.20, S D=1.56 \\
M=1.33, S D=.47\end{array}$ & $\begin{array}{l}M=4.56, S D=2.13 \\
M=1.88, S D=2.05\end{array}$ & $\begin{array}{l}M=4.34, S D=2.11 \\
M=1.27, S D=.55\end{array}$ & $\begin{array}{l}M=4.35 \\
M=1.47\end{array}$ & Total HA targets, $M=4.27$ \\
\hline $\begin{array}{l}\text { Total single participants, } \\
\qquad M=2.76\end{array}$ & $\begin{array}{l}\text { HA targets } \\
\text { LA targets }\end{array}$ & $\begin{array}{l}M=5.06, S D=1.23 \\
M=1.44, S D=.53\end{array}$ & $\begin{array}{l}M=3.33, S D=1.57 \\
M=1.16, S D=.21\end{array}$ & $\begin{array}{l}M=4.12, S D=1.57 \\
M=1.42, S D=.56\end{array}$ & $\begin{array}{l}M=4.21 \\
M=1.36\end{array}$ & Total LA targets, $M=1.40$ \\
\hline Marginal means & & $M=3.01$ & $M=2.73$ & $M=2.79$ & & \\
\hline
\end{tabular}

$H A$ high attractiveness, $L A$ low attractiveness

Participant Sexual Interest ratings were higher in the winning condition than in the control condition, which, in turn, were higher than in the losing condition, as predicted, $F(1,53)=$ $11.69, p=0.001$. For mated participants, there were no significant differences between participants in the winning $(M=2.77, S D=.85)$, losing $(M=3.22, S D=1.83)$, and control $(M=2.81, S D=1.11)$ conditions, $F(2,37)=.45, p=0.64$, $\left.\eta_{p}=.16\right)$.
Although the Relationship Status $\times$ Competition $\times$ Target Attractiveness interaction was not significant, $F(2,88)=$ 1.33, $p=0.27, \eta_{p}=17$, an examination of Fig. 1 reveals that the Participant Relationship Status by Competition interaction was driven by single participants' ratings of highattractiveness women. Subsequent Tukey's HSD follow-up tests and a contrast analysis revealed that single participants had significantly higher Participant Sexual Interest ratings in
Fig. 1 Mean participant sexual interest ratings (on an eight-point Likert-type scale) for mated participants (top) and single participants (bottom), separated by target attractiveness (i.e., $H A$ : high attractiveness; $L A$ : low attractiveness)

\section{Participant Sexual Interest (Mated Participants)}

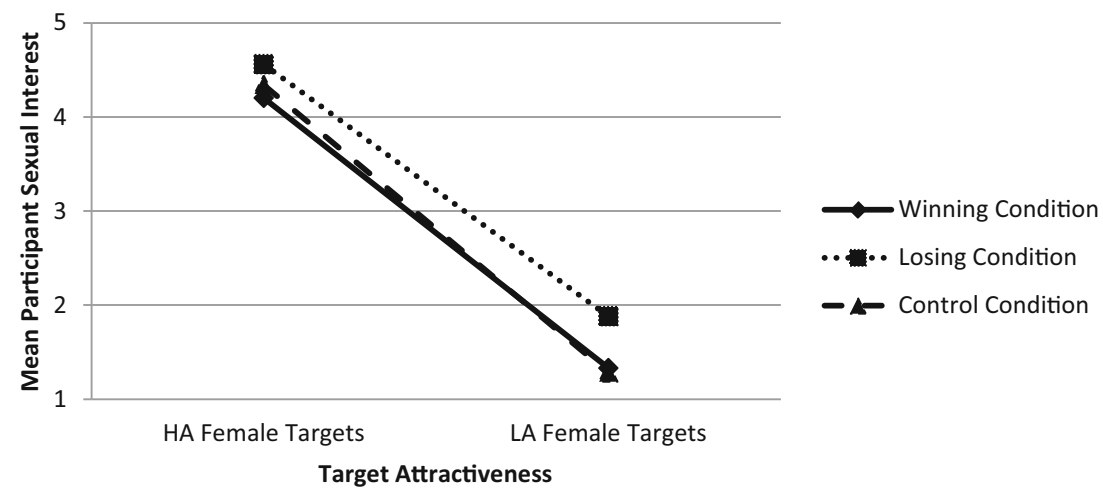

\section{Participant Sexual Interest (Single Participants)}

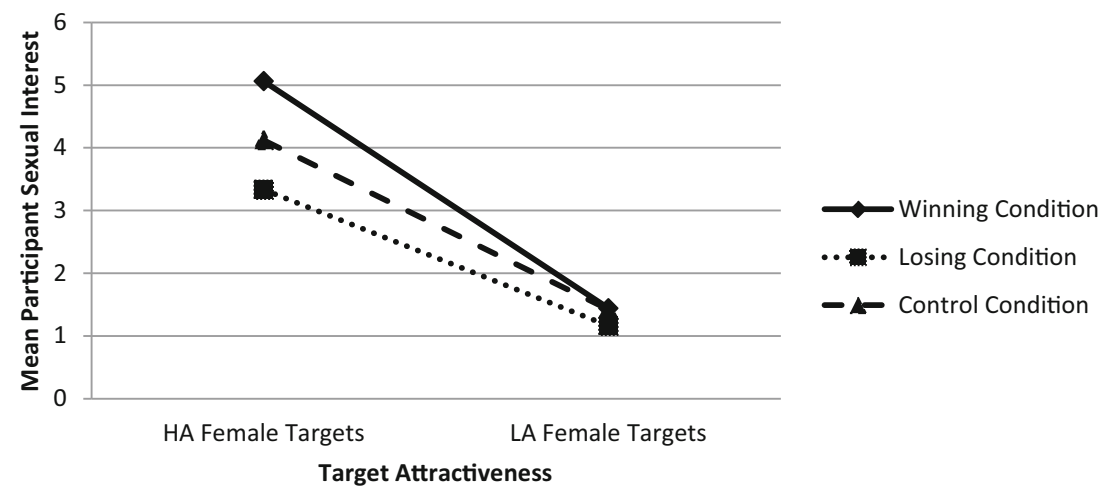


the winning than the losing condition only for the highattractiveness women. No differences in Participant Sexual Interest ratings were found for the mated participants for either the high- or low-attractiveness women or for the single participants for the low-attractiveness women.

\section{Target Sexual Interest}

Target Sexual Interest was calculated as the average of two questions measuring the amount of sexual interest that participants assigned to the target women on an eight-point Likerttype scale (high attractiveness: $\alpha=.76$; low attractiveness: $\alpha=.77$ ) (see Table 1). Mean Target Sexual Interest scores by Participant Relationship Status, Competition, and Target Attractiveness are presented in Table 3. These scores were entered into a 2 (Participant Relationship Status: mated vs. single) by 3 (Competition: winning vs. losing. vs. control) by 2 (Target Attractiveness: high attractiveness vs. low attractiveness) mixed-design ANOVA, with Participant Relationship Status and Competition being between-subjects factors and Target Attractiveness being a within-subjects factor.

The analysis produced a significant main effect of Target Attractiveness, $F(1,90)=28.81, p<0.001, \eta_{p}=.49$, such that participants gave high-attractiveness women higher Target Sexual Interest ratings $(M=4.21, S D=1.58)$ than they gave low-attractiveness women $(M=3.11, S D=1.82)$. There were no significant main effects or interactions involving Competition or Participant Relationship Status.

Separate follow-up analyses were conducted on each of the two individual questions contained within the Target Sexual Interest measure. For one question, "How sexually aroused is this woman?", there was a marginally significant Target Attractiveness by Competition by Participant Relationship Status interaction, $F(2,90)=2.91, p=0.06, \eta_{p}=.25$, which was in the predicted direction - but only for single participants' ratings of high-attractiveness women's sexual arousal. That is, single participants who were in the winning condition tended to rate high-attractiveness women as being more sexually aroused $(M=4.11, S D=1.91)$ than single participants in the control $(M=3.74, S D=1.42)$ and losing $(M=3.07$, $S D=1.71$ ) conditions, respectively. The predicted effects were not obtained in regard to single participants' ratings of lowattractiveness women (winning condition, $M=2.44, S D=1.92$; losing condition, $M=3.00, S D=2.27$; control condition, $M=3.17, S D=1.87$ ), nor in regard to mated participants' ratings of either high-attractiveness women (winning condition, $M=3.79, S D=1.93$; losing condition, $M=4.31, S D=1.97$; control condition, $M=3.74, S D=1.42$ ) or low-attractiveness women (winning condition, $M=2.86, S D=1.41$; losing condition, $M=2.69, S D=2.14$; control condition, $M=2.38, S D=$ 1.89). A contrast analysis of single participants' responses to this question produced a marginally significant linear trend across levels of competitive feedback, but only for their ratings of high-attractiveness women (i.e., single participants in the winning condition rated high-attractiveness women as being more sexually aroused than did single participants in the control condition, who, in turn, rated high-attractiveness women as being more sexually aroused than did single participants in the losing condition): high-attractiveness, $F(1,53)=$ $3.22, p=0.08$; low-attractiveness, $\quad F(1,53)=.63$, $p=0.43$.

Analysis of the other Target Sexual Interest question ("How interested is this woman in having sex?") produced only a significant main effect of Target Attractiveness, $F(1,90)=20.01, p<0.001, \eta_{p}=.43$, such that highattractiveness women were rated as being more interested in having sex $(M=4.54, S D=1.77)$ than low-attractiveness women $(M=3.43, S D=2.14)$. There were no other significant main or interactive effects.

\section{Discussion}

The hypothesized effect of competitive outcomes on men's sexual interest was supported by single men's Participant Sexual Interest ratings, whereas competitive outcomes had no effect on the sexual interest of men in sexually active heterosexual relationships. Specifically, single men who were given winning feedback exhibited the highest average sexual interest score (as

Table 3 Means and standard deviations for target sexual interest by relationship status, competition condition, and target attractiveness (rated on an eight-point scale, $1=$ "not at all"; $8=$ "very")

\begin{tabular}{|c|c|c|c|c|c|c|}
\hline & & \multicolumn{3}{|l|}{ Condition } & \multirow[t]{2}{*}{ Marginal Means } & \\
\hline & & Winning & Losing & Control & & \\
\hline $\begin{array}{l}\text { Total mated participants, } \\
\qquad M=3.65\end{array}$ & $\begin{array}{l}\text { HA targets } \\
\text { LA targets }\end{array}$ & $\begin{array}{l}M=4.18, S D=1.67 \\
M=3.04, S D=1.61\end{array}$ & $\begin{array}{l}M=4.19, S D=1.81 \\
M=2.96, S D=2.30\end{array}$ & $\begin{array}{l}M=4.77, S D=1.60 \\
M=2.77, S D=1.79\end{array}$ & $\begin{array}{l}M=4.38 \\
M=2.93\end{array}$ & Total HA targets, $M=4.21$ \\
\hline $\begin{array}{l}\text { Total single participants, } \\
\qquad M=3.66\end{array}$ & $\begin{array}{l}\text { HA targets } \\
\text { LA targets }\end{array}$ & $\begin{array}{l}M=4.50, S D=1.77 \\
M=2.69, S D=1.83\end{array}$ & $\begin{array}{l}M=3.70, S D=1.35 \\
M=3.50, S D=2.04\end{array}$ & $\begin{array}{l}M=4.04, S D=1.38 \\
M=3.50, S D=1.56\end{array}$ & $\begin{array}{l}M=4.10 \\
M=3.24\end{array}$ & Total LA targets, $M=3.11$ \\
\hline Marginal means & & $M=3.60$ & $M=3.59$ & $M=3.77$ & & \\
\hline
\end{tabular}

$H A$ high attractiveness, $L A$ low attractiveness 
measured by their self-reported sexual interest in photographed women), followed by single men in the control and losing conditions, respectively. Furthermore, the effects were strongest for single men's ratings of high-attractiveness women. Men were also more likely to over-perceive sexual interest in highattractiveness women than low-attractiveness women, suggesting a disposition aimed at seizing mating opportunities with fertile, genetically healthy women, consistent with error management theory (Haselton and Buss 2000). However, contrary to what was hypothesized, there were no significant effects of competitive outcomes on men's average attributions of sexual interest to women - though there was a marginally significant interaction in the predicted direction between competitive outcomes and relationship status on a question measuring men's attributions of arousal to high-attractiveness women, with single men in the winning condition attributing more sexual arousal to high-attractiveness women than single men in the control and losing conditions. The reason for this partial result may be due to the small number of questions (2) pertaining to men's attribution of sexual interest to women; future research should incorporate more diverse measures of men's attribution of sexual interest to women as a function of differential competitive outcomes.

The differential effects of competitive outcomes on mated versus single men's sexual interest is consistent with prior research tracking the relative decreases in testosterone experienced by men in ever-increasing stages of romantic commitment, with marriage and (especially) fatherhood being associated with context-dependent reductions in testosterone and mate-seeking behavior (e.g., Gettler et al. 2011; Gray et al. 2002; Kuzawa et al. 2009; McIntyre et al. 2006). It is possible that, along with such absolute reductions in testosterone, men who are in relationships may undergo a decrease in testosterone-level sensitivity to context-dependent shifts in social status, as would normally occur upon a man's victory or defeat in a competition with another man (cf. Gladue et al. 1989). The ultimate, evolutionary explanation for such proximate-level differences in testosterone regulation may be the high cost of competitiveness and mate-seeking behavior. Specifically, men in relationships might weigh the relative tradeoffs of continued intrasexual competition and mateseeking behavior differently than single men. That is, for men who are already mated, the reproductive benefits of increases in sexual interest as a result of winning might not be worth the associated costs of losing one's time, resources, reputation, and, most importantly, one's current romantic partner, as well as experiencing the immunosuppressive costs of testosterone and the likelihood of physical injury and death as a result of continued competition and mate-seeking behavior. Conversely, losing should not be expected to decrease mated men's sexual interest because these men can continue to engage in sexual activity with their romantic partners. At a proximate level, this may be accomplished by the protective effects of being in a relationship on men's self-esteem, positive self- concept, and/or self-perceived mate-value-factors that may contribute to the maintenance of mated men's sexual interest in the face of defeat. Of course, whether being in a relationship is associated with such a protective effect on men's sexual interest is an open, empirical question.

It is also possible that social pressure or demand characteristics might have caused mated men in the winning condition to report less sexual interest than they actually experienced. That this is likely not the entire story is reflected by the fact that all participants' (whether mated or single) reported greater sexual interest in high-attractiveness women than in lowattractiveness women.

One limitation is that our relationship status measure (i.e., "Are you currently in a sexually active relationship?") may not have accurately distinguished single men from mated men. For example, individuals are capable of being in sexual relationships without being either committed or monogamous, creating the possibility that de facto single men were categorized as mated. Conversely, although perhaps less common, individuals can be in a long-term romantic relationship without being sexually active, creating the possibility that de facto mated men were categorized as single. Because of these reasons, the previous analysis of the effects of relationship status on participants' competition-induced changes in sexual interest should be interpreted with these limitations in mind. In the future, we aim to use a more detailed measure of relationship status, which distinguishes sexual from non-sexual, and longfrom short-term relationships.

It is also possible that the current results might reflect the differential effect of competition on men's mate preferences as opposed to sexual interest. Changes in mate preferences may explain why the effects of competitive outcomes on single participants were mostly confined to ratings of high-attractiveness women. That is, the current findings may reflect single men's increased preferences for attractive women following a win and decreased preferences for attractive women following a loss, as opposed to a more general change in sexual interest following a competitive outcome. This possibility might explain why there were no significant effects of competitive outcomes on single participants' sexual interest in low-attractiveness women. Because there were no female targets of intermediate attractiveness (a limitation that we hope to address in subsequent research), there might have been floor effects in men's ratings of sexual interest in low-attractiveness women-floor effects that may have hidden other effects of competitive outcomes on participants' mate preferences. For example, rather than downregulating their sexual interest entirely, it is possible that men who experience a loss might become more interested in pursuing women of intermediate attractiveness. Furthermore, it would make evolutionary sense if, in addition to experiencing a general increase in sexual interest, single winners would be more interested in pursuing high-attractiveness women-women who might be more interested in them now that their social status 
has increased. Although there were no differences between men's and women's ratings of the photographed women's attractiveness prior to their inclusion in the main study, the fact that there were more female than male raters calls for a more controlled and confound-reducing measure of target facial attractiveness as it relates to competition-induced shifts in either men's sexual interest or mate preferences.

It is also not clear if mated participants' sexual interest is unperturbed by competitive outcomes; it could be that mated participants' sexual interest in their partners, rather than the photographed women, is being affected by competitive outcomes - a possibility that cannot be ruled out by the present study. A related limitation is that all of the photographed women were Caucasian, which may have confounded some participants' responses. For these reasons, it may be better to interpret the Participant Sexual Interest questions as measuring participants' sexual interest in specific women rather than a general sexual interest in all women. It is necessary for subsequent investigations to differentiate the effect of competition on men's changes in sexual interest versus mate preferences and, in so doing, to arrive at an empirically cogent definition of each construct.

\section{Future Directions}

This study is limited in that no testosterone assays were collected from participants, rendering our theoretical rationale for the mediating role of testosterone incomplete. In the future, we aim to fill this gap by tracking competitors' testosterone as it relates to competitive outcomes and measures of sexual psychology. Investigators might also do well to examine whether a reversal of what was observed in the present study might also be a possibility - that is, does cuing sex-related thinking cause men to become more competitive? This possibility is attested to by the fact that young, single men are disproportionately the most likely to commit violent crimes and engage in warfare (Daly and Wilson 1998). Furthermore, Imhoff et al. (2013) found that sexual priming indeed led to increases in men's aggression, but only in men prone to sexual narcissism. Thus, the complex link between sex and competitiveness might be dependent on a host of individual differences that have yet to be tracked. Likewise, it is necessary to determine whether the present results are applicable outside of intrasexual competitive contexts, such as to competitions between men and women. Although competition is associated with increases in both men's and women's testsosterone (especially when there are opposite-sex individuals present; Miller et al. 2012), the relationship between winning, losing, and women's sexual behavior has not been sufficiently studied. It likewise remains an open question as to whether individuals may undermine other individuals' sexual interest by sending false, manipulative signals of their own victory or of their competitors' defeat. Finally, the relationship between men's competitiveness and sexual behavior is an important area of investigation because of its implications for predicting rape and sexual coercion during warfare and other instances of male-male competition.

Acknowledgements We thank Todd Shackelford, Ryne Sherman, Robin Vallacher, and three anonymous reviewers for their comments and suggestions on earlier versions of this manuscript.

\section{Appendix}

Participants' rating data were initially submitted to factor analyses, conducted separately for the high-attractiveness and lowattractiveness ratings. Factors were extracted with principal component analysis, using Varimax rotation with Kaiser Normalization. Four identical factors with eigenvalues greater than 1 were extracted from both high-attractiveness target questions and low-attractiveness target questions. The four identical factors included "Participant Sexual Interest," "Target Positive Characteristics," "Target Sexual Interest," and "Target Conscientiousness," with eigenvalues 5.94, 2.83, 1.48, and 1.73 for high-attractiveness questions and 5.51, 2.45, 1.52 and 1.07 for low-attractiveness questions, respectively. Lowattractiveness questions had an additional "Target Positive Affect" factor (eigenvalue 1.35). Across both sets, all sexual interest (participant + target) questions had high loadings (greater than .7) on the first factor ("Participant Sexual Interest"), accounting for $37.10 \%$ of the variance in high-attractiveness questions and $34.44 \%$ of the variance in low-attractiveness questions. Questions pertaining to target "intelligence," and qualities such as being "hardworking" and "courageous," loaded highly (greater than .5) on the second factor ("Target Positive Characteristics"), accounting for $17.7 \%$ of the variance in highattractiveness questions and $15.29 \%$ of the variance in lowattractiveness questions. Questions pertaining to target "arousal" and target "interest in sex" had the highest loadings (greater than $.8)$ on the third factor ("Target Sexual Interest"), explaining $9.24 \%$ of the variance in high-attractiveness questions and $9.49 \%$ of the variance in low-attractiveness questions (therefore, separating each measure by "Participant" and "Target" sexual interest categories was warranted). Questions pertaining to how "strict" or "hardworking" a target is (i.e., the "Target Conscientiousness" factor) had the highest loadings (greater than 0.3 ) on the fourth factor for high-attractiveness questions and the fifth factor for low-attractiveness questions, explaining $7.33 \%$ and $6.67 \%$ of the variance, respectively. Questions gauging how "happy" or "adventurous" a target is had the highest loadings (greater than 0.7) on the fourth factor ("Target Positive Affect") in low-attractiveness questions, explaining $8.46 \%$ of the variance. Cumulatively, the factors explained $71.38 \%$ of the variance in high-attractiveness questions and $74.35 \%$ of the variance in low-attractiveness questions (for a list of all questions, see Table 1). 


\section{References}

Alonso-Alvarez, C., Bertrand, S., Faivre, B., Chastel, O., \& Sorci, G. (2007). Testosterone and oxidative stress: the oxidation handicap hypothesis. Proceedings of the Royal Society B, 274, 819-825.

Archer, J. (2006). Testosterone and human aggression: an evaluation of the challenge hypothesis. Neuroscience and Biobehavioral Reviews, 30, 319-345.

Bernhardt, P. C., Dabbs, J. M., Jr., Fielden, J. A., \& Lutter, C. D. (1998). Testosterone changes during vicarious experiences of winning and losing among fans at sporting events. Physiology \& Behavior, 65(1), 59-62.

Buss, D. M. (1989). Sex differences in human mate preferences: evolutionary hypotheses tested in 37 cultures. Behavioral and Brain Sciences, 12, 1-49.

Buss, D. M., \& Dedden, L. A. (1990). Derogation of competitors. Journal of Social and Personal Relationships, 7, 395-422.

Daly, M., \& Wilson, M. (1998). Homicide. Hawthorne: Aldine de Gruyter.

Darwin, C. (1871/2006). The descent of man, and selection in relation to sex. In E. O. Wilson (Ed.), From so simple a beginning: the four great books of Charles Darwin (pp. 767-1248). New York: Norton.

Ebner, N. C., Riediger, M., \& Lindenberger, U. (2010). FACES-A database of facial expressions in young, middle-aged, and older women and men: development and validation. Behavior Research Methods, 42(1), 351-362.

Ellis, B. J. (2004). Timing of pubertal maturation in girls: an integrated life history approach. Psychological Bulletin, 130(6), 920-958.

Gettler, L. T., McDade, T. W., \& Kuzawa, C. W. (2011). Cortisol and testosterone in Filipino young adult men: evidence for co-regulation of both hormones by fatherhood and relationship status. American Journal of Human Biology, 23, 609-620.

Gladue, B. A., Boechler, M., \& McCaul, K. (1989). Hormonal response to competition in human males. Aggressive Behavior, 15, 409-422.

Gonzalez-Bono, E., Salvador, A., Ricarte, J., Serrano, M. A., \& Arnedo, M. (2000). Testosterone and attribution of successful competition. Aggressive Behavior, 26, 235-240.

Gray, P. B., Kahlenberg, S. M., Barrett, E. S., Lipson, S. F., \& Ellison, P. T. (2002). Marriage and fatherhood are associated with lower testosterone in males. Evoluiton and Human Behavior, 23, 193-201.

Haselton, M. G., \& Buss, D. M. (2000). Error management theory: a new perspective on biases in cross-sex mind reading. Journal of Personality and Social Psychology, 78(1), 81-91.
Haselton, M. G., Buss, D. M., Oubaid, V., \& Angleitner, A. (2005). Sex, lies, and strategic interference: the psychology of deception between the sexes. Personality and Social Psychology Bulletin, 31, 3-23.

Hill, K., \& Kaplan, H. (1999). Life history traits in humans: theory and empirical studies. Annual Review of Anthropology, 28, 397-430.

Imhoff, R., Bergmann, X., Banse, R., \& Schmidt, A. F. (2013). Exploring the automatic undercurrents of sexual narcissism: individual differences in the sex-aggression link. Archives of Sexual Behavior, 42(6), 1033-1041.

Kuzawa, C. W., Gettler, L., Muller, M. N., McDade, T. W., \& Feranil, A. B. (2009). Fatherhood, pairbonding and testosterone in the Philippines. Hormones and Behavior, 56, 429-435.

Markey, P. M., \& Markey, C. N. (2010). Changes in pornography-seeking behaviors following political elections: an examination of the challenge hypothesis. Evolution and Human Behavior, 31, 442-446.

Markey, P., \& Markey, C. (2011). Pornography-seeking behaviors following midterm political elections in the United States: a replication of the challenge hypothesis. Computers in Human Behavior, 27, 1262-1264.

Mazur, A., Booth, A., \& Dabbs, J. M., Jr. (1992). Testosterone and chess competition. Social Psychology Quarterly, 55(1), 70-77.

McIntyre, M., Gangestad, S. W., Gray, P. B., Chapman, J. F., Burnham, T. C., O'Rourke, M. T., \& Thornhill, R. (2006). Romantic involvement often reduces men's testosterone levels - but not always: the moderating role of extrapair sexual interest. Journal of Personality and Social Psychology, 91, 642-651.

Miller, S. L., Maner, J. K., \& McNulty, J. K. (2012). Adaptive attunement to the sex of individuals at a competition: the ratio of opposite- to same-sex individuals correlates with changes in competitors' testosterone levels. Evolution and Human Behavior, 33, 57-63.

Rosenthal, R., Rosnow, R. L., \& Rubin, D. B. (2000). Contrast and effect sizes in behavioral research: a correlational approach. Cambridge: Cambridge University Press.

Rupp, H. A., \& Wallen, K. (2007). Relationship between testosterone and interest in sexual stimuli: the effect of experience. Hormones and Behavior, 52, 581-589.

Saad, G., \& Vongas, J. G. (2009). The effect of conspicuous consumption on men's testosterone levels. Organizational Behavior and Human Decision Processes, 110(2), 80-92.

Shackelford, T. K., Schmitt, D. P., \& Buss, D. M. (2005). Universal dimensions of human mate preferences. Personality and Individual Differences, 39, 447-458.

Stanton, S. J., Beehner, J. C., Saini, E. K., Kuhn, C. M., \& LaBar, K. S. (2009). Dominance, politics, and physiology: voters' testosterone changes on the night of the 2008 United States presidential election. PLOS ONE, 4(10), 1-6. 